\title{
(C) OPEN ACCESS \\ Common cold in Team Finland during 2018 Winter Olympic Games (PyeongChang): epidemiology, diagnosis including molecular point-of-care testing (POCT) and treatment
}

\author{
Maarit Valtonen, ${ }^{\oplus 1}$ Matti Waris, ${ }^{2,3}$ Tytti Vuorinen, ${ }_{1}^{2,3}$ Erkki Eerola, ${ }^{2,4}$ Antti J Hakanen, ${ }^{2,4}$ \\ Katja Mjosund, ${ }^{5}$ Wilma Grönroos, ${ }^{5}$ Olli J Heinonen, ${ }^{5}$ Olli Ruuskanen ${ }^{6}$
}

${ }^{1}$ Research Center for Olympic Sports, Jyväskylä, Finland 2 Institute of Biomedicine, University of Turku, Turku, Finland

${ }^{3}$ Department of Clinical Virology, Turku University Hospital, Turku, Finland

${ }^{4}$ Department of Clinical Microbiology, Turku University Hospital, Turku, Finland ${ }^{5}$ Paavo Nurmi Centre and Unit of Health and Physical Activity, University of Turku, Turku, Finland

${ }^{6}$ Department of Paediatrics, Turku University Hospital Research Centre, Turku, Finland

\section{Correspondence to}

Dr Maarit Valtonen, Research Center for Olympic Sports, Jyväskylä 40700, Finland; maarit.valtonen@kihu.fi

Accepted 13 May 2019 Published Online First 29 May 2019

\section{ABSTRACT \\ Objectives The common cold is the main cause of} medical time loss in elite sport. Rapid diagnosis has been a challenge that may be amenable to molecular point-ofcare testing (POCT).

Methods We performed a prospective observational study of the common cold in Team Finland during the 2018 Winter Olympic Games. There were 44 elite athletes and 68 staff members. The chief physician recorded the symptoms of the common cold daily on a standardised form. Two nasal swabs were taken at the onset of symptoms. One swab was analysed within 45 min using a molecular POCT for respiratory syncytial virus and influenza $A$ and $B$ viruses. After the Games, the other swab was tested for 16 possible causative respiratory viruses using PCR in laboratory-based testing. Results 20 out of $44(45 \%)$ athletes and 22 out of $68(32 \%)$ staff members experienced symptoms of the common cold during a median stay of 21 days. Eleven (26\%) samples tested virus-positive using POCT. All subjects with influenza $(n=6)$ and 32 close contacts were treated with oseltamivir. The aetiology of the common cold was finally detected in $75 \%$ of the athletes and $68 \%$ of the staff members. Seven virus clusters were identified. They were caused by coronaviruses 229E, NL63 and OC43, influenza B virus, respiratory syncytial virus $A$, rhinovirus and human metapneumovirus. The virus infections spread readily within the team, most commonly within the same sport discipline.

Conclusions The cold was indeed a common illness in Team Finland during the Winter Olympic Games. POCT proved to be clinically valuable, especially for influenza. The aetiology of the common cold was identified in most cases.

\section{INTRODUCTION}

Elite athletes are predisposed to the common cold due to heavy physical and mental stress which may suppress both innate and adaptive immunity. ${ }^{1-5}$ Air travel, human crowding, housing with other athletes and competition all increase the susceptibility of an elite athlete to the common cold. ${ }^{6}$ The Winter Olympic Games take place during periods of low temperatures and its timing coincides with epidemics of many respiratory viruses. The common cold has been said to be 'the most dreaded opponent' at the Winter Olympic Games, and may ruin the athlete's long-term goal of success. ${ }^{7}$
The common cold is a prevalent, complex and heterogeneous illness. ${ }^{8}$ More than 10 species of respiratory viruses exist, and they contain hundreds of subspecies with different immunopathologies. ${ }^{9} 10$ Signs and symptoms of different viral infections overlap, and it is not possible to identify the aetiological agent on clinical grounds alone. ${ }^{1112}$ Antiviral treatment is only available for influenza, but virus-specific preventive measures may reduce the transmission of illnesses. ${ }^{13} 14$

The aim of our prospective observational study was to investigate the occurrence and aetiology of the common cold in Team Finland during the 2018 Winter Olympic Games. We used recently developed molecular multiplexed POCT for influenza A and $\mathrm{B}$ viruses and respiratory syncytial virus at the Games site. ${ }^{1516}$ After the Games, we used laboratory-based PCR testing to detect 16 possible causative respiratory viruses.

\section{METHODS}

Study planning and participants

This prospective observational study was carried out during the Winter Olympic Games in PyeongChang, South Korea between 26 January and 28 February 2018. During the Games, the temperature and humidity measured by Team Finland varied between $-17^{\circ} \mathrm{C}$ and $+8^{\circ} \mathrm{C}$ and between $12 \%$ and $77 \%$, respectively. Monitoring of the common cold was provided to Team Finland members who stayed in the Olympic Village (45 athletes and 46 supportive staff members) and the two hotels outside the village (22 staff members) (figure 1). The mean age of the athletes $(n=45)$ was 27 (SD 6 ) years and the mean age of the staff members $(n=68)$ was 44 (SD 9). Thirteen athletes and 10 staff members were female. The team members participated in the monitoring for the entire duration of their Olympic trip, starting from their departure from Helsinki airport and finishing with their return to Helsinki airport, thus including two intercontinental flights with duration of 8 hours 50 min and 9 hours $50 \mathrm{~min}$. On their departure, all team members were reported to be asymptomatic and healthy, except one subject with nasal congestion. The team members stayed in PyeongChang for a median length of 21 days (with a range of 10-32 days). They lived in groups of 5-6 in 3-bedroom to 4-bedroom flats in a single block of 16 flats. 


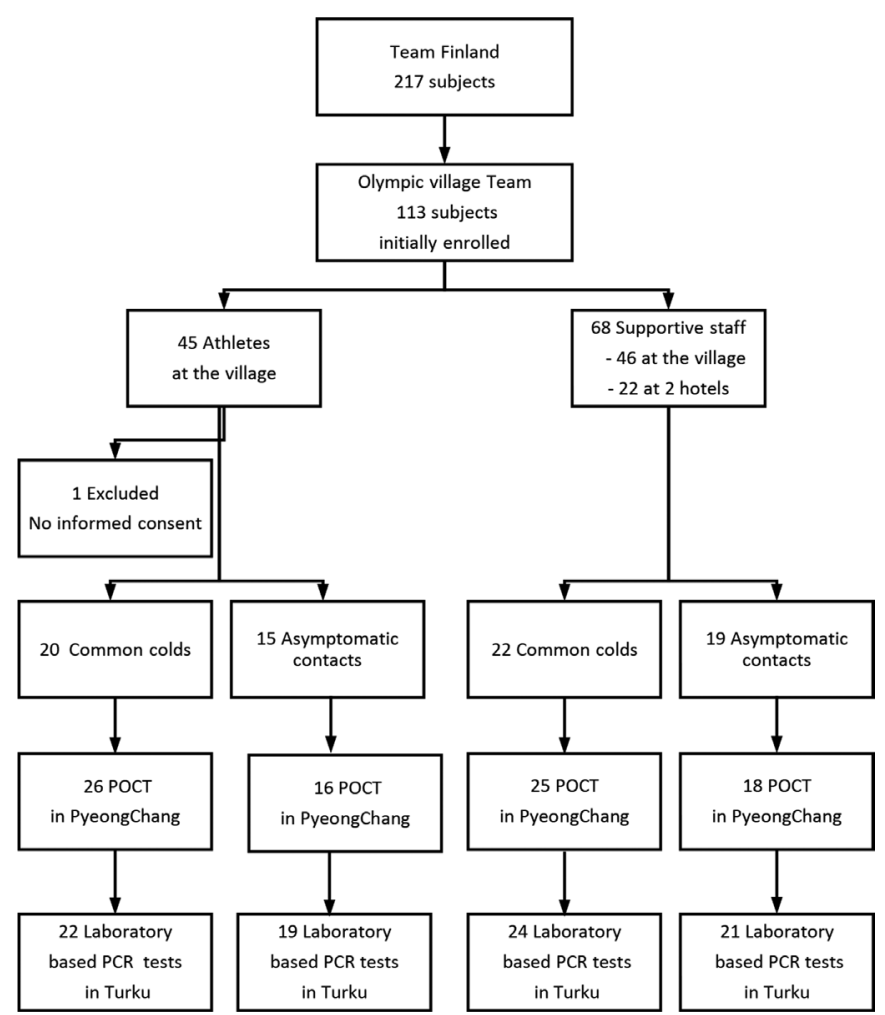

Figure 1 Flow chart of the study. More than one mucus sample was taken from 28 participants. Eleven POCT samples were not available for retesting in the laboratory. Due to lack of POCT reagents onsite, 12 samples were only tested in the laboratory. POCT, point-of-care testing. 1 Total No. of tests performed including subjects tested more than once.

All team members were instructed to immediately report symptoms of upper respiratory tract infection to the chief physician (MV), who stayed in the same building. At the onset of a symptom, two nasal mucus specimens (one from each nostril) were collected at a depth of 3-4 cm using flocked nasal swabs (503CS01, Copan Flock Technologies, Brescia, Italy). One specimen was used immediately for POCT and the other was refrigerated in a dry storage tube (553C, Copan Flock Technologies, Brescia, Italy) in the team's medical room. Swabs were also taken from subjects exposed to a patient with the common cold. Specimens for POCT were collected as part of the medical care of the team members.

All study-related activities were conducted according to good clinical practice, which includes the provisions of the Declaration of Helsinki.

\section{Assessment of illness}

The common cold was defined as the acute onset of any of the following symptoms: sore throat, rhinorrhoea, nasal congestion and cough. ${ }^{8}$ In addition, fever (an axillary temperature $\geq 37.8^{\circ} \mathrm{C}$ ), hoarseness and lethargy were recorded on a standardised form in the evening on a four-point severity scale $(0=$ absent, $1=$ mild, $2=$ moderate and $3=$ severe). ${ }^{17}$ The total symptom score for the first 5 days of illness was calculated.

\section{Microbiological studies}

A fast, automated POCT, the Cepheid Xpert Influenza+RSV Xpress Assay, was used according to the manufacturer's instructions. ${ }^{16}$ A nasal swab was suspended into $3 \mathrm{~mL}$ of universal transport medium (UTM, Copan Italia, Brescia, Italy) and 300 $\mu \mathrm{L}$ of suspension was added into the assay cartridge, which was then loaded into the Cepheid GeneXpert II instrument. After a processing time of $30 \mathrm{~min}$, the test reading was recorded.

For laboratory testing, stored specimens were suspended into $1 \mathrm{~mL}$ of phosphate-buffered saline. Nucleic acids were extracted from $500 \mu \mathrm{L}$ aliquots of the suspended specimens with the MagNA Pure 96 System using a MagNA Pure 96 DNA Viral NA LV 2.0 kit (Roche Diagnostics, Mannheim, Germany) with the Pathogen Universal 5003.1 protocol and an elution volume of $50 \mu \mathrm{L}$. The extracted nucleic acids were stored at $-70^{\circ} \mathrm{C}$ between analyses. Allplex Respiratory Panels 1-4 (Seegene, Seoul, South Korea) and the CFX96 (Bio-Rad Laboratories, Hercules, California, USA) instrument were used in accordance with the manufacturer's instructions to detect respiratory syncytial virus A and B, adenovirus, influenza $\mathrm{A}$ and $\mathrm{B}$ viruses, rhinovirus, parainfluenza type 1-4 viruses, human coronavirus 229E, OC43 and NL63, human bocavirus and human metapneumovirus using $8 \mu \mathrm{L}$ of each specimen per panel. The AllPlex Respiratory Panel also detected the following bacteria: Streptococcus pneumoniae, non-typeable Haemophilus influenzae, Moraxella catarrhalis, Bordetella pertussis, Chlamydophila pneumoniae and Mycoplasma pneumoniae. A laboratory-designed triplex RT-PCR assay for influenza A, A/H1pdm09 and B viruses was performed as described earlier, with the exception that NxtScript DNA Master (Roche Diagnostics, Mannheim, Germany) and Mic PCR instrument (Bio Molecular Systems, Upper Coomera, QLD, Queensland, Australia) were used for the PCR step. ${ }^{18}$ In addition, respiratory syncytial virus, rhinoviruses and enteroviruses were detected using a triplex RT-PCR assay as described earlier, with the exception that SensiFAST Probe No-ROX kit (Bioline, Luckenwalde, Germany), and Mic PCR instrument were used for the PCR step. ${ }^{19}$

A virus cluster was defined as three detections of the same virus during the median length of 3 weeks. This was considered an unusual aggregation event.

\section{Statistics}

The difference between proportions was tested with a binomial standard normal deviation (SND) test and 95\% CIs were calculated accordingly.

\section{RESULTS}

\section{Occurrence of the common cold}

Forty-two out of 112 team members reported symptoms of respiratory infection during the study period of 10-32 days (median 21 days). There were 20 athletes (45\%) and 22 (32\%) staff members ( $p=0.123,95 \% \mathrm{CI}-5.2$ to 31.2$)$. Two athletes and two staff members suffered from a febrile illness. The mean duration of the symptoms was 8.3 (SD 7.8) days and 8.7 (SD 8.9) days in the athletes and the staff, respectively. One athlete and one staff member suffered from symptoms throughout their entire stay in the village (figure 2). Symptoms were mostly mild, and the mean total severity score was 6.4 (SD 5.9) for the athletes and 7.3 (SD 5.7) for the staff (table 1). Only one athlete lost a competition on 1 day due to a respiratory infection.

\section{Aetiology of the common cold detected by molecular POCT} Onsite, the aetiology of respiratory infections was identified in 11 of $42(26 \%)$ symptomatic cases. Before the Games, two cases of influenza B were detected by local healthcare services using antigen detection. POCT in the team's medical room detected one case of influenza A virus, three cases of influenza B virus and five cases of respiratory syncytial virus A. The aetiology of the common cold was identified in six athletes and in five staff members. All six patients with an influenza virus infection were 


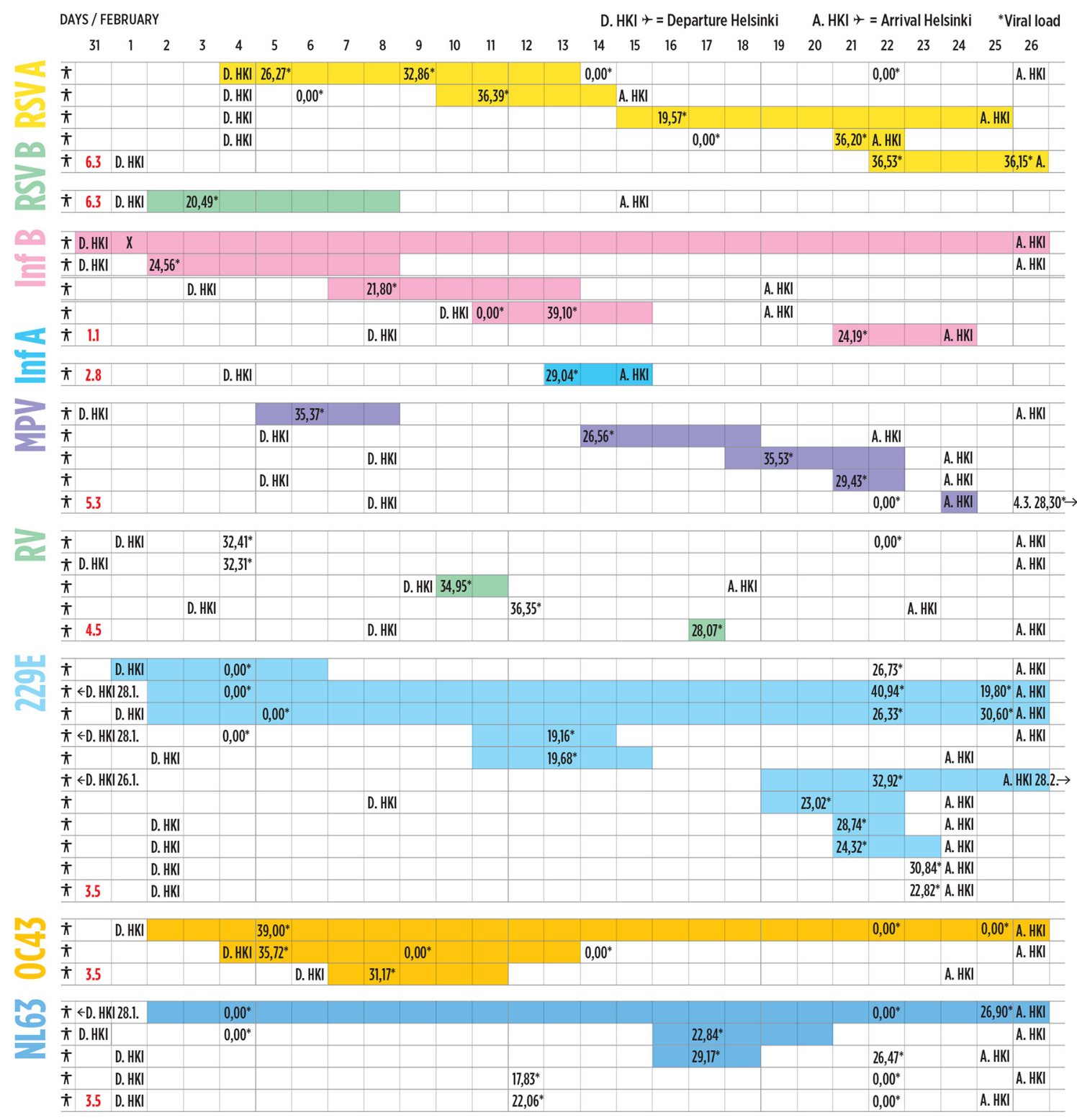

Figure 2 Occurrence and aetiology of the common cold. The figure shows the departure day (D) from Helsinki and the arrival day (A) to Helsinki of each subject who got the common cold during the Games. The coloured bars represent different viruses and the length of the bar the duration of respiratory symptoms in days. The red numbers show the incubation periods the viruses. ${ }^{34}$ * The numbers in the coloured bars give $\mathrm{Ct}$-values which reflect inversely viral load, $<27$ reflects high viral load. Number 0 means virus negative test; $X$ means diagnosed by the antigen detection by the local healthcare. $\quad$ RSV A, respiratory syncytial virus $A$; $\quad R S V B$, respiratory syncytial virus $B$; Inf $B$, influenza $B$ virus; $\quad$ Inf $A$, influenza A virus; $\quad$ MPV, human metapneumovirus; $\quad$ RV, rhinovirus; $\quad 229 \mathrm{E}$, human coronavirus 229E; $\quad$ OC43, human coronavirus 0C43; $\quad$ NL63, human coronavirus NL63.

treated with oseltamivir. Oseltamivir prophylaxis was given to their 32 contacts (11 athletes). None of them developed a symptomatic infection.

Aetiology of the common cold detected by multiplex-PCRtesting in the laboratory

The aetiology of the common cold was finally detected in 30 of 42 patients, in 15 of $20(75 \%)$ athletes and in 15 of $22(68 \%)$ staff members. Nine different respiratory viruses were identified. Coronaviruses (229E, NL63 and OC43) were the most commonly detected viruses (table 1 ). Two participants had two viruses (respiratory syncytial virus A and coronavirus OC43; and coronavirus 229E and coronavirus NL63). One athlete suffered from two different coronavirus (OC43 and 229E) infections 20 days apart. The recorded PCR threshold values mostly indicated low viral loads (table 1 , figure 2 ). In five athletes and nine staff members $(p=0.117)$, the PCR cycle threshold values were $<27$, indicating high viral load (figure 2). In 8 out of 20 virus-positive cases, a previous or later nasal specimen was virus-negative.

Nasal mucus samples were taken from 34 asymptomatic subjects due to close contact to a symptomatic subject. Eight samples were virus-positive (rhinovirus 3, coronavirus 229E 3, coronavirus NL63 2).

Multiplexed PCR-testing for nasal bacteria identified $H$. influenzae in seven subjects and S. pneumoniae in two subjects. Co-detection with a respiratory virus was found in three out of nine cases. No cases of atypical bacteria were identified. Clinically no cases of probable bacterial infections were recorded. 


\section{Original article}

Table 1 Characteristics of respiratory virus infections in athletes and staff

\begin{tabular}{|c|c|c|c|c|c|c|c|c|c|}
\hline & $\begin{array}{l}\text { Coronavirus } \\
229 \mathrm{E}\end{array}$ & Influenza B & RSV A & Rhinovirus & Metapneumovirus & Coronavirus NL63 & Coronavirus $\mathrm{OC} 43$ & RSV B & Influenza A \\
\hline \multicolumn{10}{|l|}{ Team Finland } \\
\hline $\mathrm{N}$ & 11 & 5 & 5 & 5 & 5 & 5 & 3 & 1 & 1 \\
\hline \multicolumn{10}{|l|}{ Asymptomatic } \\
\hline $\mathrm{N}$ & 3 & 0 & 0 & 3 & 0 & 2 & 0 & 0 & 0 \\
\hline$C_{t}$-value mean (SD) & $26.8(3.3)$ & & & $33.7(1.9)$ & & $22.1(3.5)$ & & & \\
\hline$C_{\mathrm{t}}$-value $<27$ (no) & 2 & 0 & 0 & 0 & 0 & 2 & 0 & 0 & 0 \\
\hline \multicolumn{10}{|l|}{ Athletes -- symptomatic } \\
\hline $\mathrm{N}$ & 2 & 1 & 4 & 1 & 4 & 1 & 2 & 1 & 1 \\
\hline Severity score median & 3.5 & 26.0 & 8.0 & 2.0 & 5.0 & 3.0 & 6.5 & 5.0 & 3.0 \\
\hline Duration mean, days (SD) & $13.5(16.3)$ & 7.0 & $8.7(3.2)$ & 2.0 & $4.0(1.7)$ & 3.0 & $18.0(11.3)$ & 7.0 & 3.0 \\
\hline $\mathrm{C}_{\mathrm{t}}$-value mean (SD) & $27.5(1.2)$ & 39.1 & $26.9(3.7)$ & 35.0 & $30.0(3.4)$ & 29.2 & $37.4(1.6)$ & 20.5 & 29.0 \\
\hline$C_{t}$-value <27 (no) & 1 & 0 & 2 & 0 & 1 & 0 & 0 & 1 & 0 \\
\hline \multicolumn{10}{|l|}{ Staff-symptomatic } \\
\hline $\mathrm{N}$ & 6 & 4 & 1 & 1 & 1 & 2 & 1 & 0 & 0 \\
\hline Severity score median & 5.0 & 15.5 & Unknown* & 1.0 & 4.0 & 6.5 & 5.0 & & \\
\hline Duration mean, days (SD) & $7.7(8.6)$ & $11.3(10.6)$ & Unknown* & 1.0 & 4.0 & $15.0(14.1)$ & 5.0 & & \\
\hline$C_{t}$-value mean (SD) & $26.7(7.8)$ & $26.3(3.7)$ & 36.5 & 28.1 & 35.4 & $24.9(2.0)$ & 31.2 & & \\
\hline$C_{\mathrm{t}}$-value $<27$ (no) & 4 & 3 & 0 & 0 & 0 & 2 & 0 & & \\
\hline
\end{tabular}

* The subject left the Games with signs and symptoms of illness. The $C_{t}$-value inversely reflects the virus load, $<27$ reflects a high viral load.

RSV A and B, respiratory syncytial virus $A$ and $B$.

Eleven specimens were not available for retesting in the laboratory. All other POCT results were confirmed in the laboratory.

Four athletes competed with mild symptoms of the common cold. One athlete competed 5 days after the onset of an influenza $\mathrm{B}$ infection, another competed 5 days after the onset of a respiratory syncytial virus $A$ infection and two athletes competed five days after the onset of a metapneumovirus infection.

Transmission of the common cold within the team

One subject reported nasal congestion when departing Finland. Respiratory syncytial virus A was detected at the Olympic
Village. Six days later, the neighbouring team member in the aeroplane developed symptomatic respiratory syncytial virus A -infection. The next respiratory syncytial virus A cases were identified consequently 10,16 and 17 days after the initial respiratory syncytial virus A detection.

One subject developed a febrile influenza B infection during the 9-hour outbound flight. Another subject on the same flight (seated one row behind) developed an influenza B infection 1.5 days later. Three more subjects were infected with the influenza $B$ virus. These cases were separate and were not known to be in contact with the earlier cases.

Table 2 Team Finland in the PyeongChang Olympic village and in two hotels outside the village

\begin{tabular}{|c|c|c|c|c|c|}
\hline & $\mathbf{N}$ & Symptomatic N & Virus $\mathrm{N}$ & $\begin{array}{l}\text { Asymptomatic } \\
\text { tested N }\end{array}$ & Virus $\mathrm{N}$ \\
\hline \multicolumn{6}{|l|}{ Athletes } \\
\hline Alpine skiing and freestyle & 4 & 3 & Influenza B 1 & - & - \\
\hline Biathlon & 8 & 1 & Coronavirus 229E 1 & 1 & Coronavirus $229 \mathrm{E} 1$ \\
\hline Cross-country skiing & 14 & 10 & $\begin{array}{l}\text { RSV A 3, RSV A+coronavirus OC43 1, RSV B } \\
\text { 1, coronavirus } 229 E+\text { coronavirus OC43 1, } \\
\text { coronavirus NL63 } 1\end{array}$ & 10 & Coronavirus NL63 2 \\
\hline Nordic Combined & 5 & 2 & Metapneumovirus 2 & 4 & - \\
\hline Snowboarding & 7 & 1 & Rhinovirus 1 & - & - \\
\hline Ski jumping & 6 & 3 & Metapneumovirus 2, influenza A 1 & - & - \\
\hline \multicolumn{6}{|l|}{ Staff members } \\
\hline Coaches & 18 & 6 & RSV A (1), rhinovirus 1, coronavirus 229E 3 & 4 & Rhinovirus 1 \\
\hline General managers & 7 & 4 & Metapneumovirus 1, coronavirus 229E 2 & 3 & - \\
\hline Communications & 2 & 0 & - & 1 & - \\
\hline Ski technicians & 27 & 7 & $\begin{array}{l}\text { Influenza B 3, coronavirus 229E 1, coronavirus } \\
\text { NL63 } 1\end{array}$ & 7 & Coronavirus OC43 1 \\
\hline Physicians & 3 & 0 & - & 1 & Rhinovirus 1 \\
\hline Physiotherapists & 5 & 3 & $\begin{array}{l}\text { Coronavirus } 229 \mathrm{E}+\text { coronavirus NL63 1, } \\
\text { influenza B } 1\end{array}$ & 1 & - \\
\hline Masseuses & 4 & 1 & Negative & 2 & Coronavirus 229E 2 \\
\hline Mental coaches & 2 & 1 & Negative & - & - \\
\hline
\end{tabular}

RSV $A$ and $B$, respiratory syncytial virus $A$ and $B$. 
One subject developed nasal congestion during the 9-hour flight, later detected to be a respiratory syncytial virus B infection. The subject was seated in business class and was isolated for 4 days in the Olympic Village. No other team member was infected with respiratory syncytial virus B.

One subject reported a sore throat and mild lethargy 6 days after the departure. Metapneumovirus was detected. Metapneumovirus was detected in team members consequently 8, 13, 15 and 18 days after the initial metapneumovirus detection.

Rhinovirus was detected in two samples from asymptomatic individuals 3 days and 4 days after their departure from Finland. One subject later arrived in the village with a symptomatic rhinovirus infection. One more subject developed nasal congestion in the village and one asymptomatic subject staying outside the village was predisposed to influenza B infection. In both cases, rhinovirus infection was later laboratory-confirmed. According to the incubation time and known contacts, the rhinovirus infections in the team were considered separate.

Coronavirus 229E was detected in two subjects on February 13. The following cases were identified consequently 7,8 (2 cases), 9 (4 cases) and 10 ( 2 cases) days after the initial detections. Three of these infections were asymptomatic. Coronavirus OC43 was identified in one subject 1 day after the subject departed Helsinki. Two further cases were identified 2 and 4 days after the initial case. Two asymptomatic coronavirus NL63 cases were identified on February 12. Two and one symptomatic subjects were detected 5 and 13 days later.

Altogether seven virus clusters were identified. Four clusters (respiratory syncytial virus A, metapneumovirus, coronaviruses 229E and NL63) occurred within the same sport discipline (table 2). Inter-disciplinary transmission was rare (data not shown).

\section{DISCUSSION}

We discuss three main findings from this prospective observational study. First, $45 \%$ of the elite athletes and $32 \%$ of the staff members suffered from the symptoms of the common cold during the median stay of 3 weeks at the Winter Olympic Games. Second, POCT multiplex PCR diagnostics rapidly detected influenza $A$ and $B$ virus, and respiratory syncytial virus infections. Third, the probable aetiology of the common cold could be detected in $75 \%$ of the athletes and $68 \%$ of the staff members. Coronaviruses were the most common causative agents. Unexpectedly, clusters of seven respiratory viruses were found within the team.

\section{Occurrence of the common cold during the winter games}

Two previous studies by the IOC reported $2 \%$ and $4 \%$ incidences of respiratory infections in elite athletes during the Vancouver 2010 and the Sochi 2014 Olympic Winter Games, respectively. ${ }^{20} 21$ Our observation (45\%) contrasts those observations. The IOC's reporting system may not be reliable because it is based on voluntary reporting by team physicians, who may not be properly informed within the team. At the onset of the Games, in our study, the team physician informed all team members about the monitoring of the common cold. She stayed in the same building as the team which allowed for daily encounters with the majority of team members. Even one symptom or mild symptoms were reported. ${ }^{22}$ In agreement with our observations, $48 \%$ of 44 Norwegian cross-country skiers self-reported becoming ill during or 10 days immediately after the Tour de $\mathrm{Ski}^{23}$
Aetiology of the common cold in elite athletes

Our study is the first to detect the aetiology of respiratory infections in elite athletes using molecular POCT at a major event. All available POCT virus diagnoses (positive and negative) were later confirmed at a laboratory. Diagnostics had clinical implications in the treatment and prevention of influenza A and B infections. In addition to early treatment with oseltamivir, POCT enabled effective post-contact oseltamivir prophylaxis for close contacts, for example, those living in the same accommodation or travelling on the same flight or in the same vehicle. ${ }^{14}$ The isolation of infected team members was initiated after the onset of symptoms and continued for 3-4 days (ie, the most infectious period). ${ }^{24-27}$

We detected the probable causative virus in $75 \%$ of the elite athletes with the common cold. Causality is supported by a $4 \%-6 \%$ occurrence of respiratory viruses in asymptomatic adults. ${ }^{2829}$ Only two earlier studies carried out in Australia in warm climate conditions have investigated the viral aetiology of acute respiratory symptoms in summer sport elite athletes. In one study the recovery rate was $29 \%$ and in the other it was $27 \% .^{3031}$ These low detection rates led to the commonly cited conclusion that in the majority of cases the symptoms could be due to non-infectious airway inflammation. Our observations in winter sport athletes do not support that conclusion. The virus recovery rate of $75 \%$ in elite athletes is as high as in other aetiological studies in adults. ${ }^{9} 10$ A higher viral recovery rate in adults may not be obtained because PCR tests may detect only $50 \%-90 \%$ of serologically diagnosed respiratory virus infections. ${ }^{13} 32$ The occurrence of respiratory infections tended to be more common in elite athletes than in other team members. The difference may be explained by higher physical and psychological stress in elite athletes. It is of interest that the severity of illness among the athletes did not differ from that among the staff (table 1). Before and during the Winter Games, influenza and respiratory syncytial virus epidemics were occurring in Finland and influenza and coronavirus epidemics were under way in South Korea. The prevailing virus epidemics obviously contributed to the transmission of the infections.

\section{Transmission of the common cold}

In three subjects, the symptoms of the common cold-one caused by influenza $B$ virus and the others by respiratory syncytial virus $\mathrm{A}$ and $\mathrm{B}-$ developed during the 9-hour flight from Helsinki to Seoul. Two patients seemed to transmit the illness to another team member during the flight. Long-haul air travel is a wellknown risk factor for the transmission of contagious diseases. One person with influenza can transmit the infection to 5-10 people during an intercontinental flight. ${ }^{33}$ Two cases of coronavirus OC43 infection were most probably travelling during the incubation period of the infection (3.5 days) and developed the illness within 2-3 days after arrival in the Olympic Village. ${ }^{27} 34$ In addition, the first cases of rhinovirus and metapneumovirus infections were detected during the first week, suggesting that these infections also originated in Finland. ${ }^{34}$ In addition to direct or indirect contact and droplets, respiratory viruses can spread via exhaled aerosols, even while talking. ${ }^{35} 36$ Viruses may stay infectious on a surface for hours or days. The most commonly detected coronavirus 229E, stays infectious on common surfaces for at least 7 days. $^{37}$ Interestingly, it was recently shown that viruses can also spread through toilet flushing. ${ }^{38}$ Ultimately, 7 clusters of different respiratory virus infections were recorded. Important factors in the transmission of the viruses were the 
housing with other athletes and the sport discipline (table 1). Competition venues may be a favourable environment for virus transmission. Rigorous hand washing, the use of hand sanitisers, enhanced disinfection and strict patient isolation were likely to prevent the spread of viruses within the team but were apparently not very effective (figure 2 ). This is due to the multifactorial transmission mechanisms of viral infections. ${ }^{39}$

\section{Study limitations}

The number of subjects was small. Nasal swabs were planned to be taken from symptomatic subjects as part of normal healthcare. The prevalence and clinical significance of asymptomatic infections (eg, most coronavirus and influenza infections are asymptomatic) and prolonged virus shedding (ie, infectiousness) remains unclear. The POCT diagnostics detected only three respiratory viruses. ${ }^{16}$ The 2018 influenza and respiratory syncytial virus epidemics were prominent, which may have increased our detection rate and affected the generalisability of the findings. Our study did not answer the question concerning the impact of a symptomatic or asymptomatic respiratory virus infection on an elite athlete's performance.

\section{CONCLUSIONS}

Molecular POCT diagnostics proved clinically valuable. The aetiology of the common cold was identified in the majority of cases. The viruses were readily transmitted within the team. We

\section{What are the findings?}

On Team Finland during the 2018 Winter Olympic Games, $45 \%$ of athletes and $32 \%$ of the support staff suffered from the common cold during a median observation period of 21 days.

- We used a fast and automated molecular point-of-care test (POCT) for influenza A and B viruses and respiratory syncytial virus on site. This allowed identification of the aetiology of respiratory infections in 11 of $42(26 \%)$ symptomatic cases. All subjects with influenza and close contact with individuals with influenza were treated with oseltamivir.

- In the laboratory the aetiology of the common cold was detected in $75 \%$ of the elite athletes. These athletes did not suffer from 'non-infectious airway inflammation in athletes'.

- Nine different respiratory viruses were detected, causing seven clusters of respiratory infections within the team. Coronaviruses were the most common viruses. Most viruses probably originated in Finland.

\section{How might it impact on clinical practice in the future?}

- POCT diagnostics for a comprehensive range of respiratory viruses should be made available at major sport events. POCT will improve the proper treatment, for example, targeted treatment of influenza, decrease unnecessary antibiotic treatment and enhance timely isolation to decrease viral transmission.

- The incidence of influenza virus infection reinforces the need for influenza vaccination in sport teams.

- At major sport events, healthcare providers should share information concerning detected respiratory virus infections to all teams to prevent an epidemics of respiratory viruses. believe comprehensive viral POCT is useful at major sporting events.

Acknowledgements We would like to thank Cepheid, South Korea, for supplying the Cepheid Xpert Flu+RSV Xpress System. The study design, data collection, analysis and conclusions in this study are those of the authors. The investigators acknowledge with gratitude the International Olympic Committee for giving us permission to use the Cepheid Xpert Flu+RSV Xpress System in the Olympic Village. We thank the Olympic Committee of Finland for its support.

Contributors MV, MW, OJH and OR contributed to the design of the study. MV carried out the field study. MW, TV, EE and AJK contributed to laboratory testing. MV, MW, WG and OR contributed to data analysis. All authors contributed to the interpretation of study results. MV and OR prepared the first draft of the manuscript and all authors reviewed and approved the manuscript.

Funding This study was funded by the Jenny and Antti Wihuri Foundation and Signe and Ane Gyllenberg Foundation.

Competing interests None declared.

Patient consent for publication Not required.

Ethics approval Hospital District of Southwest Finland ETMK 37/2018.

Provenance and peer review Not commissioned; externally peer reviewed.

Data sharing statement All data relevant to the study are included in the article or uploaded as supplementary information.

Open access This is an open access article distributed in accordance with the Creative Commons Attribution Non Commercial (CC BY-NC 4.0) license, which permits others to distribute, remix, adapt, build upon this work non-commercially, and license their derivative works on different terms, provided the original work is properly cited, appropriate credit is given, any changes made indicated, and the use is non-commercial. See: http://creativecommons.org/licenses/by-nc/4.0/.

\section{REFERENCES}

1 Walsh NP, Gleeson M, Pyne DB, et al. Position statement. Part two: maintaining immune health. Exerc Immunol Rev 2011;17:64-103.

2 Simpson RJ, Kunz $\mathrm{H}$, Agha $\mathrm{N}$, et al. Exercise and the regulation of immune functions. Prog Mol Biol Trans/ Sci 2015;135:355-80.

3 Colbey C, Cox AJ, Pyne DB, et al. Upper respiratory symptoms, gut health and mucosal immunity in athletes. Sports Med 2018:48:65-77.

4 Shaw DM, Merien F, Braakhuis A, et al. T-cells and their cytokine production: the anti-inflammatory and immunosuppressive effects of strenuous exercise. Cytokine 2018;104:136-42.

5 Walsh NP. Recommendations to maintain immune health in athletes. Eur J Sport Sc 2018;18:820-31.

6 Svendsen IS, Taylor IM, Tønnessen E, et al. Training-related and competition-related risk factors for respiratory tract and gastrointestinal infections in elite cross-country skiers. Br J Sports Med 2016;50:809-15.

7 The New York Times. The most dreaded opponent at the Olympics: the common cold, 2018. Available: https:/www.nytimes.com/2018/02/11/sports/olympics/commoncold-athletes.html

8 Heikkinen T, Järvinen A. The common cold. Lancet 2003:361:51-9.

9 Mäkelä MJ, Puhakka T, Ruuskanen 0, et al. Viruses and bacteria in the etiology of the common cold. J Clin Microbiol 1998:36:539-42.

10 van Beek J, Veenhoven RH, Bruin JP, et al. Influenza-like illness incidence is not reduced by influenza vaccination in a cohort of older adults, despite effectively reducing laboratory-confirmed influenza virus infections. J Infect Dis 2017:216:415-24.

11 Byington CL, Ampofo K, Stockmann C, et al. Community surveillance of respiratory viruses among families in the Utah better identification of Germs-Longitudinal viral Epidemiology (BIG-LoVE) study. Clin Infect Dis 2015;61:1217-24.

$12 \mathrm{Ma}$ X, Conrad T, Alchikh M, et al. Can we distinguish respiratory viral infections based on clinical features? A prospective pediatric cohort compared to systematic literature review. Rev Med Virol 2018;28:e1997.

13 Lau MSY, Cowling BJ, Cook AR, et al. Inferring influenza dynamics and control in households. Proc Natl Acad Sci U S A 2015;112:9094-9.

14 Paules C, Subbarao K. Influenza. Lancet 2017:390:697-708.

15 Brendish NJ, Malachira AK, Armstrong L, et al. Routine molecular point-of-care testing for respiratory viruses in adults presenting to hospital with acute respiratory illness (ResPOC): a pragmatic, open-label, randomised controlled trial. Lancet Respir Med 2017:5:401-11.

16 Cohen DM, Kline J, May LS, et al. Accurate PCR detection of influenza A/B and respiratory syncytial viruses by use of Cepheid Xpert Flu+RSV Xpress assay in point-of-care settings: comparison to Prodesse ProFlu. J Clin Microbiol 2018:56:e01237-17

17 Puhakka T, Mäkelä MJ, Malmström K, et al. The common cold: effects of intranasal fluticasone propionate treatment. J Allergy Clin Immunol 1998;101:726-31. 
18 Jokela $\mathrm{P}$, Vuorinen $\mathrm{T}$, Waris $\mathrm{M}$, et al. Performance of the Alere i influenza A\&B assay and mariPOC test for the rapid detection of influenza $A$ and $B$ viruses. J Clin Virol 2015;70:72-6.

19 Osterback R, Tevaluoto T, Ylinen T, et al. Simultaneous detection and differentiation of human rhino- and enteroviruses in clinical specimens by real-time PCR with locked nucleic acid probes. J Clin Microbiol 2013;51:3960-7.

20 Engebretsen L, Steffen K, Alonso JM, et al. Sports injuries and illnesses during the winter Olympic Games 2010. Br J Sports Med 2010:44:772-80.

21 Soligard T, Steffen K, Palmer-Green D, et al. Sports injuries and illnesses in the Sochi 2014 Olympic winter games. Br J Sports Med 2015;49:441-7.

22 Ip DKM, Lau LLH, Leung NHL, et al. Viral shedding and transmission potential of asymptomatic and paucisymptomatic influenza virus infections in the community. Clin Infect Dis 2017:64:736-42.

23 Svendsen IS, Gleeson M, Haugen TA, et al. Effect of an intense period of competition on race performance and self-reported illness in elite cross-country skiers. Scand J Med Sci Sports 2015;25:846-53.

24 Lee N, Hui DSC, Zuo Z, et al. A prospective intervention study on higher-dose oseltamivir treatment in adults hospitalized with influenza A and B infections. Clin Infect Dis 2013:57:1511-9.

25 Lee N, Chan MCW, Lui GCY, et al. High viral load and respiratory failure in adults hospitalized for respiratory syncytial virus infections. J Infect Dis 2015;212:1237-40.

$26 \mathrm{Ng} \mathrm{KT}$, Oong XY, Lim SH, et al. Viral load and sequence analysis reveal the symptom severity, diversity, and transmission clusters of rhinovirus infections. Clin Infect Dis 2018;67:261-8.

27 Davis BM, Foxman B, Monto AS, et al. Human coronaviruses and other respiratory infections in young adults on a university campus: prevalence, symptoms, and shedding. Influenza Other Respir Viruses 2018;12:582-90.

28 Birger R, Morita $\mathrm{H}$, Comito $\mathrm{D}$, et al. Asymptomatic shedding of respiratory virus among an ambulatory population across seasons. mSphere 2018;3:E00249-18.
29 Sundell N, Andersson L-M, Brittain-Long R, et al. PCR detection of respiratory pathogens in asymptomatic and symptomatic adults. J Clin Microbiol 2019;57:e00716-8.

30 Spence L, Brown WJ, Pyne DB, et al. Incidence, etiology, and symptomatology of upper respiratory illness in elite athletes. Med Sci Sports Exerc 2007;39:577-86.

31 Cox AJ, Gleeson M, Pyne DB, et al. Clinical and laboratory evaluation of upper respiratory symptoms in elite athletes. Clin J Sport Med 2008;18:438-45.

32 Zhang Y, Sakthivel SK, Bramley A, et al. Serology enhances molecular diagnosis of respiratory virus infections other than influenza in children and adults hospitalized with community-acquired pneumonia. J Clin Microbiol 2017;55:79-89.

33 Leitmeyer K, Adlhoch C. Review article: influenza transmission on aircraft: a systematic literature review. Epidemiology 2016;27:743-51.

34 Lessler J, Reich NG, Brookmeyer R, et al. Incubation periods of acute respiratory viral infections: a systematic review. Lancet Infect Dis 2009;9:291-300.

35 Kulkarni H, Smith CM, Lee DDH, et al. Evidence of respiratory syncytial virus spread by aerosol. Time to revisit infection control strategies? Am J Respir Crit Care Med 2016;194:308-16.

36 Yan J, Grantham M, Pantelic J, et al. Infectious virus in exhaled breath of symptomatic seasonal influenza cases from a College Community. Proc Natl Acad Sci U S A 2018;115:1081-6

37 Bonny TS, Yezli S, Lednicky JA. Isolation and identification of human coronavirus 229E from frequently touched environmental surfaces of a university classroom that is cleaned daily. Am J Infect Control 2018;46:105-7.

38 Sassi HP, Reynolds KA, Pepper IL, et al. Evaluation of hospital-grade disinfectants on viral deposition on surfaces after toilet flushing. Am J Infect Control 2018;46:507-11.

39 Kutter JS, Spronken MI, Fraaij PL, et al. Transmission routes of respiratory viruses among humans. Curr Opin Virol 2018;28:142-51. 